\title{
The Atmospheric Water Vapor Cycle in South America and the Tropospheric Circulation
}

\author{
J. C. Labraga, O. Frumento, and M. López \\ Centro Nacional Patagónico, The National Research Council of Argentina, Puerto Madryn, Argentina
}

(Manuscript received 20 November 1998, in final form 27 May 1999)

\begin{abstract}
The main characteristics of the atmospheric water vapor cycle over the South American continent and the adjacent oceans are investigated using the 22-yr period, from 1976 to 1997, of the National Centers for Environmental Prediction-National Center for Atmospheric Research (NCEP-NCAR) 40-Year Reanalysis Project database. Precipitation rate and water vapor content fields obtained from this dataset are compared over the region with newly available observed datasets, which combine ground-based and satellite-derived observations. The temporal variation and spatial distribution of the atmospheric water vapor balance equation terms (precipitation rate, evaporation rate, and water vapor flux convergence) are examined with regard to their consistency and relative importance. The net effect of the atmospheric water vapor transport, represented in the last term of the balance equation, is decomposed into the horizontal and vertical convergence terms. The analysis of the latter highlights those regions where the topographic uplift makes a substantial contribution to the total precipitation rate. The former term is further decomposed into the stationary and transient water vapor flux contributions. The comparison of these terms with relevant characteristics of the large-scale tropospheric circulation provides a better understanding of the different precipitation regimes in South America. The mean annual balance satisfactorily closes over most of the oceanic regions. However, important imbalances found in the vicinity of high topographic features, such as in the central Andes, are attributed to large errors in the local computation of the atmospheric water vapor flux. The current results corroborate previous findings on the role of the stationary water vapor flux convergence in the spatial distribution and seasonal variation of the rainfall rate in tropical and subtropical latitudes and extend over the less-investigated continental midlatitudes. The magnitude of the transient water vapor flux convergence is, in general, lower than that of the stationary flux. Nonetheless, in some oceanic and continental regions, they are comparable and seem to be dynamically linked. This interaction, which can be explained by means of a simple transport-gradient model of the transient water vapor flux, could help to clarify the observed seasonal and interannual variability of the rainfall rate in the humid-to-dry transition zone in the southern part of the continent.
\end{abstract}

\section{Introduction}

The atmospheric water, whichever phase considered, actively participates in the energy transport process, the generation of sources and sinks of heat, and the modulation of the exchange of solar and terrestrial radiation. The understanding of the causes of climate variability observed on different timescales and the reliable estimation of climate changes produced by natural or anthropogenic factors depends, to a large extent, on a precise knowledge of the functioning of the water cycle in each component of the climate system.

One of the most important processes in the atmospheric branch of the water cycle-the water vapor and liquid water transport by the atmospheric circulation-

Corresponding author address: Dr. Juan C. Labraga, Centro Nacional Patagónico-CONICET, Blvd. Brown s/n, (9120) Puerto Madryn, Chubut, Argentina.

E-mail: labraga@cenpat.edu.ar is not yet satisfactorily quantified at the regional scale because of a poor geographic and temporal coverage of aerological observations. This is more pronounced in the Southern Hemisphere (SH), where satellite observations constitute the main source of upper-air information over the extended ocean regions and even the continents.

Understanding of the atmospheric water cycle has notably improved in the last decade because of the implementation of efficient global data assimilation and analysis systems. Some of these procedures are routinely used at climate analysis centers around the world, resulting in comprehensive datasets that are particularly suitable for atmospheric studies. Rasmusson and Mo (1996), benefiting from newly developed analysis and forecast methods, investigated the role of the rotational and divergent components of the stationary and transient water vapor flux in the hydrological balance at the global scale and over the United States. Yanai and Tomita (1998) studied the spatial distribution and the seasonal and interannual variability of heat sources and water 
vapor sinks as well as the heating mechanisms that act in different geographic regions of the world by analyzing $15 \mathrm{yr}$ of the National Centers for Environmental Prediction-National Center for Atmospheric Research (NCEP-NCAR) Reanalysis Project (NNRP) dataset (Kalnay et al. 1996).

The study of the possible effects of global warming on different aspects of the water cycle is attracting growing interest. The use of general circulation models (GCM) for theoretical investigation is currently one of the most reliable procedures. Climate change estimates are derived from long-term numerical experiments using methods of analysis of the water cycle similar to those applied in studies based on observations. As an example, Watterson (1998) estimates the possible changes in the atmospheric water vapor and precipitation distribution on the global scale and their relation with changes in the characteristics of the stationary and transient water vapor fluxes using results from double $\mathrm{CO}_{2}$ equilibrium climate experiments.

The analysis of new satellite-derived outgoing longwave radiation datasets as well as the European Centre for Medium-Range Weather Forecasts (ECMWF) analysis of the upper-air wind and specific humidity fields have resulted in improved comprehension of the annual cycle of convective activity over South America and of its relation with the large-scale circulation (Rao et al. 1996; Hastenrath 1997). Numerical experiments with GCMs help to explain how some physical factors, such as continental influence, orography, and sea surface temperature distribution, may interact with the atmospheric circulation to produce the spatial variation in the precipitation field observed over South America (Lenters and Cook 1995).

The main objective of this work is to obtain a better understanding of how some features of the large-scale circulation are related to the spatial and seasonal variations in precipitation over the South American continent and adjacent oceans. Our study of the atmospheric water vapor cycle is based on data that was provided by the NNRP (Kalnay et al. 1996), one of the most complete atmospheric databases currently available. The general characteristics of the dataset are briefly described in section 2 along with a presentation of the fundamental equations that were used and the procedures that were followed for the analysis of the water vapor transport terms. The climatic features of some of the variables involved in the atmospheric water vapor balance, such as precipitation and evaporation rates and atmospheric water vapor content, are described in section 3. We do not attempt to make an exhaustive regional validation of the NNRP products with regard to the water cycle, because in most cases it would not be possible because of the lack of independent data. However, observed climatic datasets for precipitation and water vapor content do exist; consequently, a regional comparison of these variables has been made to judge the reliability of our conclusions. This is also necessary because our analysis involves the computation of the water vapor flux field based on wind and water vapor content estimates. This variable, further decomposed into its stationary and transient components, is introduced in section 4. A summary of conclusions and some additional implications of our study are presented in section 5 .

\section{Data and analysis procedures}

The region of study includes the whole South American continent and the adjacent oceans, spanning from $20^{\circ} \mathrm{N}$ to $65^{\circ} \mathrm{S}$ and from $20^{\circ}$ to $110^{\circ} \mathrm{W}$. This research work is mainly based on the NNRP database, derived from a state-of-the-art global data assimilation system, applied to a comprehensive set of atmospheric observations, and kept unchanged over the initial reanalysis period of 1957-96 (now extending into the future). The 22-yr period from 1976 to 1997 of the NNRP is used to estimate each term of the atmospheric water vapor balance equation. The precipitation rate and the atmospheric water vapor content obtained from the NNRP are compared to shorter periods of newly available observed datasets and well-known climatologies, which will be introduced in the following section. The NNRP precipitation and evaporation rates are available on a T62 Gaussian grid (192 × 94 points). Wind components, specific humidity, and covariance, which are needed for flux computations, are provided on a uniform $2.5^{\circ}$ lat $\times 2.5^{\circ}$ long grid at eight standard pressure levels $(1000,925,850,700,600$, 500, 400, and $300 \mathrm{hPa}$ ).

The atmospheric water vapor balance equation, vertically integrated between the surface level and the top of the atmosphere and averaged in time, can be written (following Peixoto and Oort 1992) as

$$
\bar{P}=\bar{E}-\partial \bar{W} / \partial t-\boldsymbol{\nabla} \cdot \overline{\mathbf{Q}}-(\overline{q \omega})_{s} /\left(g \rho_{w}\right),
$$

where overbar indicates time average, $P$ is the precipitation rate, and $E$ is the evaporation rate. The second term on the rhs of (1) represents the time rate of change of the total precipitable water $W$, defined as

$$
\bar{W}=\left(g \rho_{w}\right)^{-1} \int_{p=p_{s}}^{p=0} \bar{q} d p,
$$

where $q$ is the specific humidity, $\rho_{w}$ is the density of water, $g$ is the acceleration of gravity, and the integral extends from the surface $\left(p=p_{s}\right)$ to the top of the atmosphere $(p=0)$. The third term on the rhs of (1) expresses the horizontal divergence of the vertically integrated horizontal water vapor flux vector $\mathbf{Q}$, which is defined as

$$
\overline{\mathbf{Q}}=\left(g \boldsymbol{\rho}_{w}\right)^{-1} \int_{p=p_{s}}^{p=0} \overline{q \mathbf{v}} d p,
$$

where $\mathbf{v}$ is the horizontal velocity vector.

The last term on the rhs of (1) results from integrating 
the vertical divergence of the water vapor flux in pressure coordinates, assuming that $q \omega$ becomes negligible at the top of the atmosphere and that the vertical velocity at the surface is zero everywhere except where wind blows over topography. The vertical integral of the continuity equation in pressure coordinates gives us an expression for the vertical velocity:

$$
\omega_{s}=-g \rho a^{-1}\left(u_{s} \cos ^{-1} \phi \partial h / \partial \lambda+v_{s} \partial h / \partial \phi\right),
$$

where $h$ is the height of the model topography, $\phi$ is the latitude, $\lambda$ is the longitude, $\rho$ is the air density, and $a$ is the mean earth radius.

According to Peixoto and Oort (1992), the rate of change of the total precipitable water is very small compared to the other terms in (1), except for short intervals of time and in the case of severe storms. Consequently, a balance between $P-E$ and the divergence of the water vapor flux is expected when (1) is averaged over a month or longer.

For a better understanding of the relationship between specific features of the atmospheric circulation and the spatial and seasonal precipitation variations, it is convenient to introduce the following decomposition of the horizontal water vapor flux vector:

$$
\overline{\mathbf{Q}}=\mathbf{Q}_{s}+\mathbf{Q}^{\prime}=\frac{1}{g \boldsymbol{\rho}_{w}}\left(\int_{p=p_{s}}^{p=0} \bar{q} \overline{\mathbf{v}} d p+\int_{p=p_{s}}^{p=0} \overline{q^{\prime} \mathbf{v}^{\prime}} d p\right),
$$

where $\mathbf{Q}_{s}$ is the stationary water vapor flux and $\mathbf{Q}^{\prime}$ is the transient flux due to perturbations in the velocity and humidity fields. The prime indicates a deviation from the time average.

\section{Thermodynamic components of the water vapor balance equation}

Before analyzing each term in (1), it is appropriate to examine the extent of the balance in water vapor at the annual scale by comparing the thermodynamic terms $P-E$ with the dynamic terms $\left[\boldsymbol{\nabla} \cdot \mathbf{Q}-(q \omega)_{s} / g \rho_{w}\right]$ on a long-term annual mean basis. Two cases are analyzed-one considering only the horizontal flux divergence (Fig. 1a) the other considering both horizontal and vertical flux divergences (Fig. 1b).

In the first case, the average imbalance over the whole region of study is $0.02 \mathrm{~mm} \mathrm{day}^{-1}$, which is about $0.6 \%$ of the mean annual precipitation in the region. The mean seasonal imbalance ranges from $0.09 \mathrm{~mm} \mathrm{day}^{-1}$ in the $\mathrm{SH}$ winter (June-August) to $-0.05 \mathrm{~mm} \mathrm{day}^{-1}$ in summer (December-February), that is, $3 \%$ and $0.2 \%$ of the mean seasonal precipitation rate in the region, respectively. Whereas over the oceanic areas there is a satisfactory quasi balance, high elevation continental areas exhibit considerable imbalance. Our approximate computation of $\mathbf{Q}$ using a finite difference expression of (3) is based on wind and specific humidity values interpolated from the original NNRP model sigma levels onto standard pressure levels (NNRP output on CD-
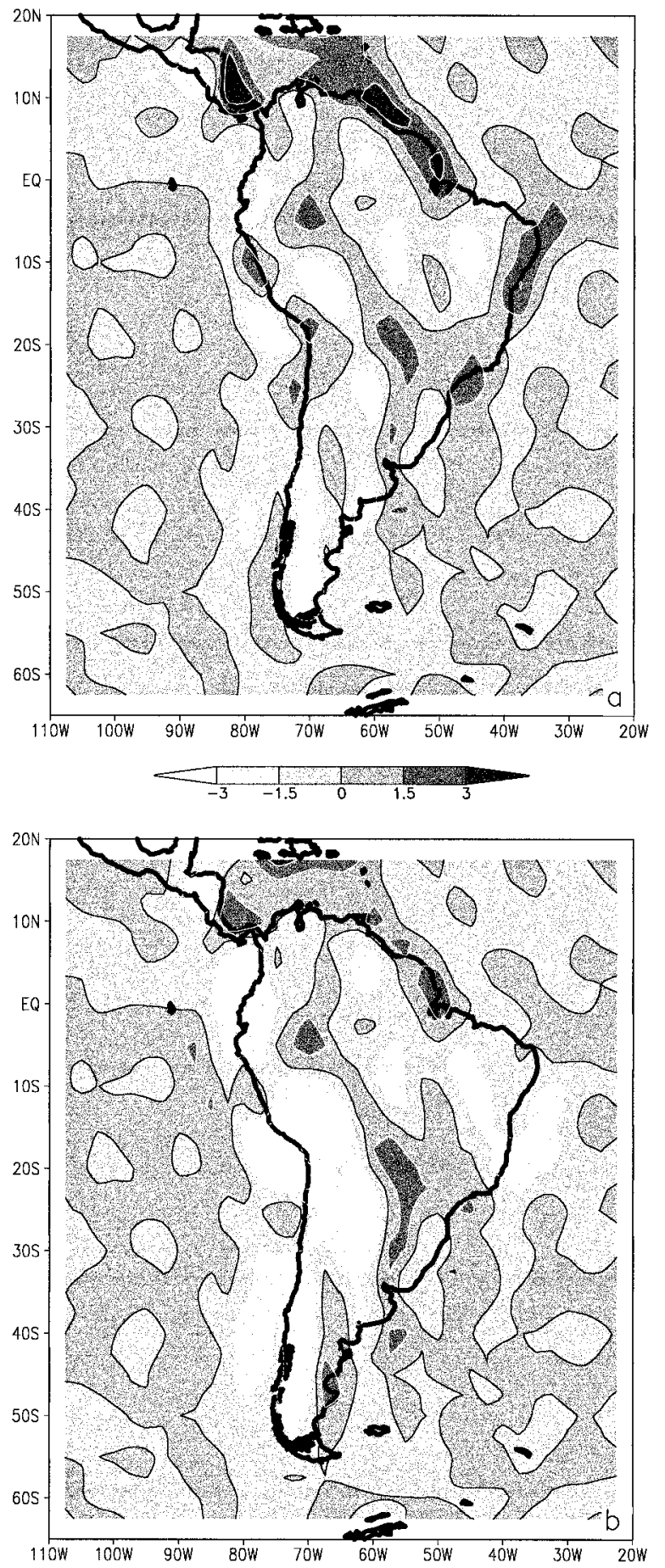

FIG. 1. (a) Long-term annual mean precipitation minus evaporation rate $(P-E)$ minus the convergence of the total (stationary plus transient) horizontal water vapor flux $\left(-\boldsymbol{\nabla} \cdot \mathbf{Q} ; \mathrm{mm} \mathrm{day}^{-1}\right)$. Computed values are based on the 1976-97 period of the NNRP. Contour interval: $2 \mathrm{~mm} \mathrm{day}^{-1}$. A solid line indicates the $0 \mathrm{~mm}$ day $^{-1}$ contour. (b) Same as (a), but minus the convergence of the vertical water vapor flux: $(q \omega)_{s} / g \rho_{w}$. 
ROM). Below the ground level, velocity components and specific humidity are set equal to the lowest model sigma level values (i.e., no extrapolation). Nevertheless, the vertical integrals in (1), (2), (3), and (5) comprise grid points above the surface only (pressure levels lower than the surface pressure). We do not expect any appreciable difference between results based on variables at sigma levels or standard pressure levels over flat terrain. However, the interpolation procedure applied to pressure levels above the surface can also be affected by nonnegligible errors over steep topography, which will propagate in the water vapor flux and flux divergence computations. The large imbalance over the slope of the Andes mountain range, which runs in the northsouth direction along the western side of the continent, could be partly attributed to this factor.

In the second case, we consider the three-dimensional flux divergence. The vertical component [last term in (1)] contributes to the balance over sloping terrain being almost negligible everywhere else (see Fig. 6, discussed in later sections). Centered finite differences were used to obtain the vertical velocity in (4), and the resulting vertical flux divergence seems to be overestimated over the slope of the central Andes between $10^{\circ}$ and $20^{\circ} \mathrm{S}$. This can be inferred from the large imbalance arising in this region and also in the southern Andes, when the vertical divergence term is included (second case, Fig. $1 b)$. Even though the real magnitude of this term is uncertain, it provides useful information about regions where its contribution to the enhancement of the rainfall rate is more likely.

\section{a. The precipitation rate}

Precipitation is one of the variables of the atmospheric water cycle that has been observed over the continents with greater detail and for longer periods. However, over the extended oceanic surfaces of the $\mathrm{SH}$, observations are scarce and observations are also scarce and discontinuous over the continents as compared with the Northern Hemisphere (NH).

A compendium and detailed analysis of the rainfall in South America and other basic climate variables linked to the hydrologic cycle can be found in Schwerdtfeger (1976). Updated descriptions of the main rainfall features over the continent can be found in Rao et al. (1996), Hastenrath (1997), and Moura and Shukla (1981).

The precipitation rate provided by the NNRP has the great advantage of uniform coverage over the whole region and throughout the period of study. However, this variable is not derived directly from observations; rather, it is a model product forced by the data assimilation procedure and obtained from 6-hourly model forecasts. It is appropriate to verify that regional climatic features described in previous works and firmly supported by observations are also well represented in this dataset. With this purpose, the NNRP mean precipitation fields are compared with climatic observations.

Figures $2 \mathrm{a}$ and $2 \mathrm{c}$ show the $\mathrm{SH}$ summer and winter mean precipitation rate in the South American region for the period of 1976 to 1997 from the NNRP dataset, the same period used in the computation of the other terms in the balance Eq. (1), shown later for comparison. This period is long enough to consider these fields as a good approach to "climatic means." Figures $2 b$ and $2 \mathrm{~d}$ show the corresponding fields from the Global Precipitation Climatology Project (GPCP) dataset (Huffman et al. 1997), obtained from the longest period available at the time of the study (9.5 yrs-from July 1987 to December 1996). Considering the characteristic yearto-year variability in precipitation, the GPCP record is rather short to produce truly climatic mean fields. However, it is long enough to capture the most outstanding features of the seasonal rainfall pattern, providing a useful mean for a descriptive comparison with the NNRP products. Similarity between the fields is also assessed by means of statistical measures, which are computed using the 9.5-yr common period.

We have used the GPCP merged analysis, incorporating precipitation estimates from low-orbiting-satellite microwave data, geosynchronous-orbiting-satellite infrared data, and rain gauge observations. The data are provided on a $2.5^{\circ}$ latitude $\times 2.5^{\circ}$ longitude global grid. Precipitation patterns during the transition seasons (not shown in the figures) were also compared, and some of their characteristics are commented on below.

Comparison of rainfall fields in Fig. 2 shows that the NNRP data adequately reproduce many of the characteristic features of the observed mean precipitation field. The most noticeable are the maximum in the equatorial Pacific and Atlantic oceans associated with the intertropical convergence zone (ITCZ); the relative minimum over the narrow band of oceanic upwelling in the eastern equatorial Pacific Ocean (more noticeably during the $\mathrm{SH}$ fall); the summer maximum over the northern Andes $\left(5^{\circ} \mathrm{N}, 75^{\circ} \mathrm{W}\right)$, which peaks during the austral spring; the high rainfall rate in summer over the Amazon basin; the minimum over northeast Brazil; the maximum over the south Atlantic convergence zone (SACZ) $\left(80^{\circ} \mathrm{S}\right.$, $35^{\circ} \mathrm{W}$ ); the semiarid region, which traverses the southern part of the continent from southern Peru and northern Chile to the southeast of Argentina; and, finally, the winter maximum over the southern Andes $\left(45^{\circ} \mathrm{S}, 75^{\circ} \mathrm{W}\right)$.

Table 1 shows the seasonal and annual mean and standard deviation of the rainfall rate for the whole region of study, obtained from the following sources: the $22-\mathrm{yr}$ period of the NNRP database, the 9.5-yr period of the GPCP dataset, and the observed climatic values of Legates and Willmott (1990) and Jaeger (1976). The observed data were previously interpolated onto the NNRP grid. The mean seasonal precipitation rates obtained from the NNRP are greater than those of Jaeger, by about $1 \%$ to $8 \%$, and of the GPCP, by $5 \%$ to $15 \%$, but lower than Legates and Willmott's, by $7 \%$ to $17 \%$. 

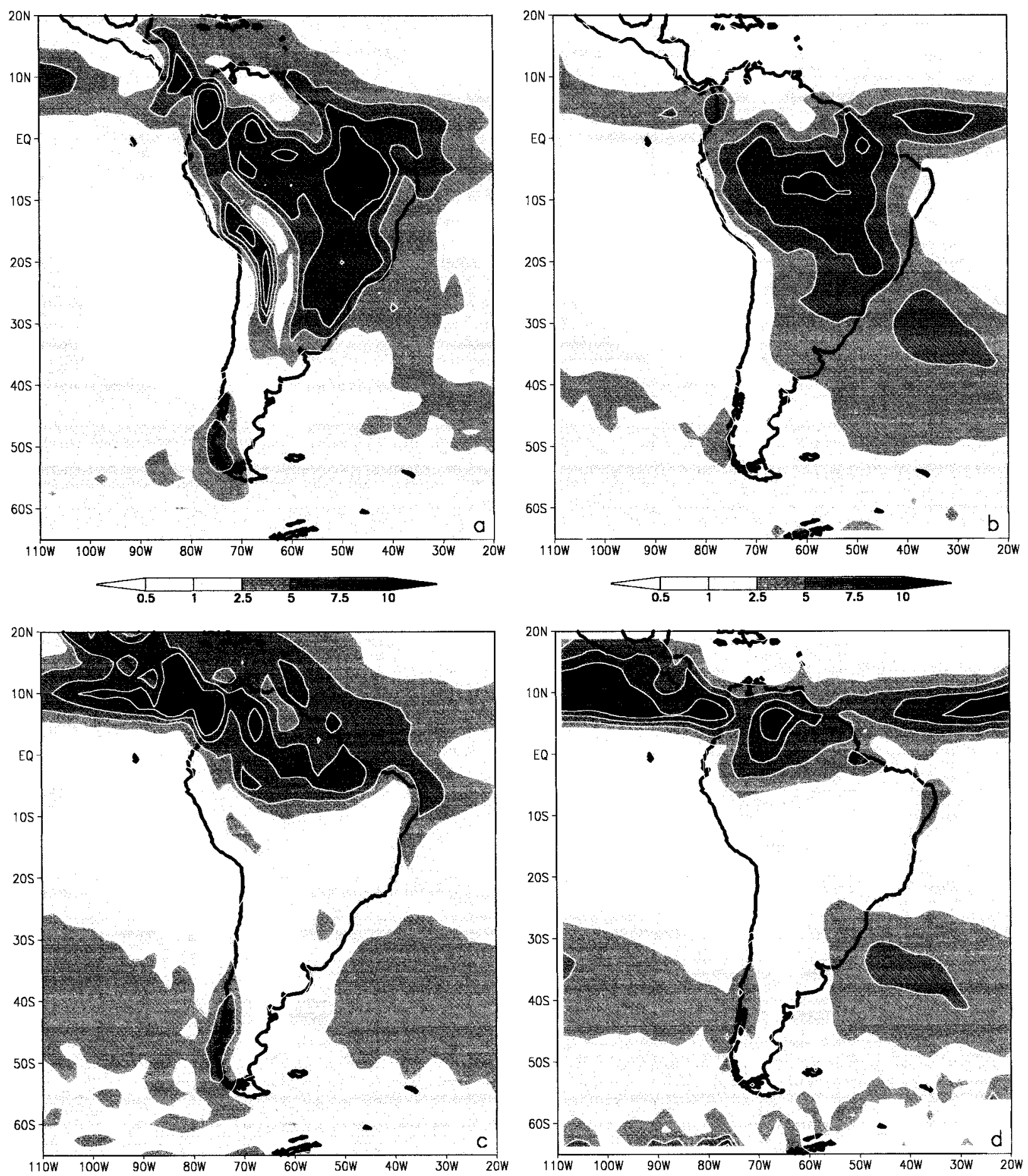

FIG. 2. SH summer (upper panels) and winter (lower panels) mean precipitation rate obtained from [(a) and (c)] the NNRP dataset, period: 1976-97, and [(b) and (d)] from the GPCP dataset, period: 1987-96. Contours at 0.5, 1.0, and $2.5 \mathrm{~mm}^{-1} \mathrm{y}^{-1}$ and higher contours at $2.5 \mathrm{~mm}$ day $^{-1}$ intervals.

Therefore, the NNRP mean precipitation rate is intermediate among observed climatic values, and the differences found among the observed climatologies are equal to or greater than those between the observed climatologies and the NNRP values. For instance, dif- ferences between GPCP and Legates and Willmott's mean precipitation rates are about $5 \%$ to $35 \%$, while GPCP values seem to be slightly closer to Jaeger's, with differences of about $5 \%$ to $13 \%$, depending upon the season considered. 
TABLE 1. Mean $\mu$ and std $\operatorname{dev} \sigma$ of the seasonal and annual mean precipitation rate ( $\mathrm{mm} \mathrm{day}^{-1}$ ), in the region from $20^{\circ} \mathrm{N}$ to $65^{\circ} \mathrm{S}$ and from $20^{\circ}$ to $110^{\circ} \mathrm{W}$, obtained from NNRP, GPCP, Legates and Willmott (L\&W) and Jaeger (J) climatic datasets.

\begin{tabular}{|c|c|c|c|c|c|c|c|c|c|c|}
\hline & \multicolumn{2}{|c|}{ Summer } & \multicolumn{2}{|c|}{ Fall } & \multicolumn{2}{|c|}{ Winter } & \multicolumn{2}{|c|}{ Spring } & \multicolumn{2}{|c|}{ Annual } \\
\hline & $\mu$ & $\sigma$ & $\mu$ & $\sigma$ & $\mu$ & $\sigma$ & $\mu$ & $\sigma$ & $\mu$ & $\sigma$ \\
\hline NNRP & 2.9 & 2.8 & 3.2 & 2.5 & 3.0 & 2.7 & 3.0 & 2.9 & 3.0 & 2.3 \\
\hline GPCP & 2.6 & 2.4 & 2.9 & 2.3 & 2.8 & 2.9 & 2.7 & 2.5 & 2.7 & 2.0 \\
\hline L\&W & 3.4 & 2.6 & 3.0 & 2.5 & 3.2 & 3.3 & 3.7 & 2.5 & 3.3 & 2.1 \\
\hline $\mathrm{J}$ & 2.9 & 2.4 & 2.9 & 2.2 & 2.9 & 2.2 & 2.8 & 2.0 & 2.9 & 1.8 \\
\hline
\end{tabular}

In Table 2, a set of statistical measures of similarity between the NNRP and the other referenced datasets is presented. The complete 22-yr mean of the NNRP is used to compare it with Legates and Willmott's and Jaeger's climatologies, while the shorter period in common (9.5 yrs) is used to compare NNRP and GPCP mean precipitation rates. The statistical measures of similarity computed are the pattern correlation coefficient $\rho$, the rms error $\varepsilon$, and the nondimensional measure of agreement $M$, defined as

$M=(2 / \pi) \sin ^{-1}\left\{1-\mathrm{mse} /\left[\sigma_{1}+\sigma_{2}+\left(m_{1}-m_{2}\right)^{2}\right]\right\}$,

where mse is the mean square error, $\sigma$ is the spatial variance, $m$ is the mean, and subindices 1 and 2 denote the compared fields. Here $M$ is a transformation of the mean square error with useful properties. It is a bounded $(0 \leq M \leq 1)$ and always well-defined symmetric measure of agreement. It approaches one linearly as the errors go to 0 . Positive values of $M$ indicate a certain degree of matching between the series with respect to permutations of the data values, and $M$ equal to one indicates a perfect agreement (Watterson 1996).

All measures of similarity indicate that the NNRP precipitation fields have a better correspondence with the GPCP fields than with the other two datasets. In general, the similarity is greater in the SH summer-fall than in the winter-spring. An exception occurs in the SH winter, when the best agreement is found between the NNRP and Jaeger's datasets. In the same table, the GPCP is compared with Jaeger's and Legates and Willmott's datasets to provide a context for the previous statistics. The relation between values in Table 2 is better understood if we think of a measure of similarity as a distance between points in the $N$-dimensional space, where $N$ is the number of grid points in the region of study. For instance, the measures of similarity between the pairs of fields NNRP-GPCP and NNRP-Jaeger are very close, but that of GPCP-Jaeger is rather low. This can be interpreted as GPCP and Jaeger's fields being at a similar distance from the field of the NNRP but in rather opposite directions.

Some regional differences are easily noticed in Fig. 2. The outstanding SH summer rainfall maximum in the central Andes $\left(10^{\circ}-30^{\circ} \mathrm{S}, 65^{\circ} \mathrm{W}\right)$, shown in the NNRP field (Fig. 2a), is not seen in the other three datasets (GPCP is the only one shown in Fig. 2b). This maximum is about $60 \%$ due to vertical moisture flux convergence, $25 \%$ due to evaporation, and $15 \%$ due to horizontal moisture flux convergence (stationary plus transient) according to numerical model estimates of Lenters and Cook (1995). Comparing observed precipitation records in Bolivia, Peru, and northwestern Argentina from Schwerdtfeger (1976) with the NNRP precipitation field and taking into account the NNRP model topography (not shown in figures), it is verified that the reanalysis overestimates precipitation rates at higher levels on the eastern slope of the central Andes (i.e., above $2000 \mathrm{~m}$ ) and underestimates it in the lowlands. A model orography smoother and much lower than reality may contribute to an inaccurate partition between the flux over and around this massive mountain barrier, affecting both the vertical and horizontal flux convergences.

During the SH summer, rainfall is abundant throughout the Amazon basin. However, while the observations indicate a maximum at about $8^{\circ} \mathrm{S}, 60^{\circ} \mathrm{W}$, in the NNRP fields, it is located at $5^{\circ} \mathrm{S}$ and $43^{\circ} \mathrm{W}$ (see Figs. $2 \mathrm{a}$ and $2 \mathrm{~b})$. The possible causes of this disagreement are examined in the following sections in relation to the other terms of the water balance equation.

TABLE 2. Pattern correlation $\rho$, rms error $\varepsilon\left(\mathrm{mm} \mathrm{day}^{-1}\right)$, and the nondimensional measure of similarity $M$ (see text for definition) between seasonal and annual mean precipitation fields obtained from NNRP, GPCP, Legates and Willmott, and Jaeger climatic datasets. Limits of the region and abbreviations as in Table 1.

\begin{tabular}{|c|c|c|c|c|c|c|c|c|c|c|c|c|c|c|c|}
\hline & \multicolumn{3}{|c|}{ Summer } & \multicolumn{3}{|c|}{ Fall } & \multicolumn{3}{|c|}{ Winter } & \multicolumn{3}{|c|}{ Spring } & \multicolumn{3}{|c|}{ Annual } \\
\hline & $\rho$ & $\varepsilon$ & $M$ & $\rho$ & $\varepsilon$ & $M$ & $\rho$ & $\varepsilon$ & $M$ & $\rho$ & $\varepsilon$ & $M$ & $\rho$ & $\varepsilon$ & $M$ \\
\hline NNRP-GPCP & 0.77 & 1.9 & 0.53 & 0.80 & 1.6 & 0.58 & 0.73 & 2.1 & 0.51 & 0.72 & 2.1 & 0.50 & 0.75 & 1.6 & 0.52 \\
\hline NNRP-L\&W & 0.63 & 2.4 & 0.42 & 0.74 & 1.8 & 0.53 & 0.63 & 2.7 & 0.41 & 0.55 & 2.7 & 0.35 & 0.65 & 1.9 & 0.44 \\
\hline NNRP-J & 0.74 & 1.9 & 0.52 & 0.72 & 1.8 & 0.50 & 0.75 & 1.8 & 0.52 & 0.68 & 2.1 & 0.44 & 0.73 & 1.6 & 0.50 \\
\hline L\&W-GPCP & 0.81 & 1.7 & 0.54 & 0.83 & 1.4 & 0.62 & 0.82 & 1.9 & 0.60 & 0.78 & 1.9 & 0.51 & 0.81 & 1.4 & 0.56 \\
\hline $\mathrm{J}-\mathrm{GPCP}$ & 0.81 & 1.5 & 0.60 & 0.76 & 1.6 & 0.55 & 0.67 & 2.2 & 0.43 & 0.63 & 2.0 & 0.42 & 0.69 & 1.5 & 0.47 \\
\hline
\end{tabular}


TABLE 3. Mean $\mu$ and std dev $\sigma$ of the seasonal and annual mean precipitable water in the total atmospheric column (mm), obtained from the NNRP database and from the NVAP observed dataset. Limits of the region as in Table 1.

\begin{tabular}{|c|c|c|c|c|c|c|c|c|c|c|}
\hline & \multicolumn{2}{|c|}{ Summer } & \multicolumn{2}{|c|}{ Fall } & \multicolumn{2}{|c|}{ Winter } & \multicolumn{2}{|c|}{ Spring } & \multicolumn{2}{|c|}{ Annual } \\
\hline & $\mu$ & $\sigma$ & $\mu$ & $\sigma$ & $\mu$ & $\sigma$ & $\mu$ & $\sigma$ & $\mu$ & $\sigma$ \\
\hline NNRP & 29.5 & 10.3 & 29.7 & 11.5 & 27.2 & 12.6 & 27.7 & 12.2 & 28.5 & 11.3 \\
\hline NVAP & 29.4 & 11.3 & 29.8 & 12.8 & 26.6 & 14.3 & 27.6 & 13.9 & 28.3 & 12.6 \\
\hline
\end{tabular}

It is interesting to note that the NNRP satisfactorily reproduces the summer maximum precipitation rate in the southeastern part of the continent between $20^{\circ}$ and $25^{\circ} \mathrm{S}$, which extends farther southeastward into the south Atlantic Ocean (Figs. 2a and 2b). This rainfall maximum is a manifestation of the SACZ and is associated with a rather narrow band of intense convective activity (Kodama 1992).

During the SH winter, a band of relatively high precipitation appears farther south (at about $30^{\circ} \mathrm{S}$ ) over the eastern part of the continent, affecting southern Brazil and all of Uruguay, and extends southeastward into the Atlantic Ocean (Figs. 2c and 2d). Its location is similar to that of the SACZ. This rainfall maximum is related to a relatively high frequency of baroclinic perturbations within the so-called storm track. In the zonal average, the $\mathrm{SH}$ winter storm track is located at about $50^{\circ} \mathrm{S}$, depending upon the latitude of the maximum standard deviation of the meridional wind component at the 300 hPa pressure level (Berbery and Vera 1996; Trenberth 1991). Across the southwestern Atlantic Ocean, however, the storm track shifts slowly to the north, reaching $35^{\circ} \mathrm{S}$ near the continent.

\section{b. The atmospheric water vapor content}

The horizontal water vapor flux is the vertical integral of the wind vector weighted by the specific humidity [see (3)]. To a large extent, it reflects the flow pattern in the lower troposphere, where most of the water vapor is concentrated. An accurate computation of $\mathbf{Q}$ and its divergence field requires a precise knowledge of the total content and vertical distribution of water vapor as well as of the horizontal wind field. We have compared the horizontal and vertical distributions of the specific humidity obtained from the NNRP with that of the Na-

TABLE 4. Annual mean precipitable water $\mu$ in the total column and in the lower, middle, and upper layer of the atmosphere $(\mathrm{mm})$ obtained from the NNRP database and from the NVAP observed dataset. Pattern correlation $\rho$, rms error $\varepsilon(\mathrm{mm})$, and the nondimensional measure of similarity $M$ between both datasets. Limits of the region as in Table 1.

\begin{tabular}{lrrccc}
\hline \hline \multicolumn{1}{c}{ Layer } & $\begin{array}{r}\mu_{\mathrm{NNRP}} \\
(\mathrm{mm})\end{array}$ & $\begin{array}{c}\mu_{\mathrm{NVAP}} \\
(\mathrm{mm})\end{array}$ & $\rho$ & $\begin{array}{c}\varepsilon \\
(\mathrm{mm})\end{array}$ & $M$ \\
\hline Surface-700 hPa & 21.7 & 21.9 & 0.97 & 2.2 & 0.84 \\
$700-500 \mathrm{hPa}$ & 5.2 & 5.2 & 0.98 & 0.7 & 0.84 \\
$500-300 \mathrm{hPa}$ & 1.6 & 1.5 & 0.89 & 0.4 & 0.68 \\
Total column & 28.5 & 28.3 & 0.98 & 2.7 & 0.86 \\
\hline
\end{tabular}

tional Aeronautics and Space Administration (NASA) Water Vapor Project (NVAP) (Randel et al. 1996) for the period of 1988 to 1995 .

The specific humidity is a class B variable within NNRP classification, a product of observational data with a strong model influence. The NVAP is a global water vapor dataset that combines radiosonde, Special Sensor Microwave/Imager, and Television Infared Observation Satellite (TIROS) Operational Vertical Sounder retrievals. The data are provided for three layers in the atmosphere-1000-700, 700-500, and 500-300 $\mathrm{hPa}-$ and in the total column, on a uniform grid of $1^{\circ}$ lat $\times 1^{\circ}$ long resolution. The NNRP total or the layer water vapor content is computed using (2). For the statistical comparison, the shorter period of the NVAP dataset was considered, and the data were interpolated onto the NNRP uniform grid.

The seasonal and annual values of the mean and the standard deviation of the total water vapor content obtained from the two datasets are compared in Table 3. The same statistical measures of likeness used for comparing precipitation fields are now used for comparing the NNRP and NVAP water vapor content fields. The mean and the measures of similarity by layer are shown in Table 4. It is encouraging to find a good degree of similarity between the two sources of atmospheric humidity data, as inferred from the large pattern correlation, small rms error, and $M$ values higher than 0.8 , except in the 500-300-hPa layer. A less similar water vapor distribution is found in the uppermost layer, but this makes a relatively small contribution to the total water vapor content.

The spatial distribution and the seasonal variation of the total water vapor content obtained from the NNRP (Figs. 3a and 3c) are in agreement with the observed NVAP climatology (Figs. 3b and 3d), as anticipated by the statistical comparison. However, some regional differences can be readily appreciated in these figures.

One of the outstanding differences is a higher water vapor content over the ITCZ in the NVAP than in the NNRP dataset throughout the year. Yet the seasonal change in location and intensity of this equatorial maximum over the Pacific and Atlantic oceans is consistent with the corresponding variations in the precipitation maximum (Figs. 2a and 2c). In winter, for instance, the precipitable water maximum intensifies in the eastern equatorial Pacific at about $10^{\circ} \mathrm{N}$ when the ITCZ is reaching its northernmost position.

An extended maximum in the water vapor content is 

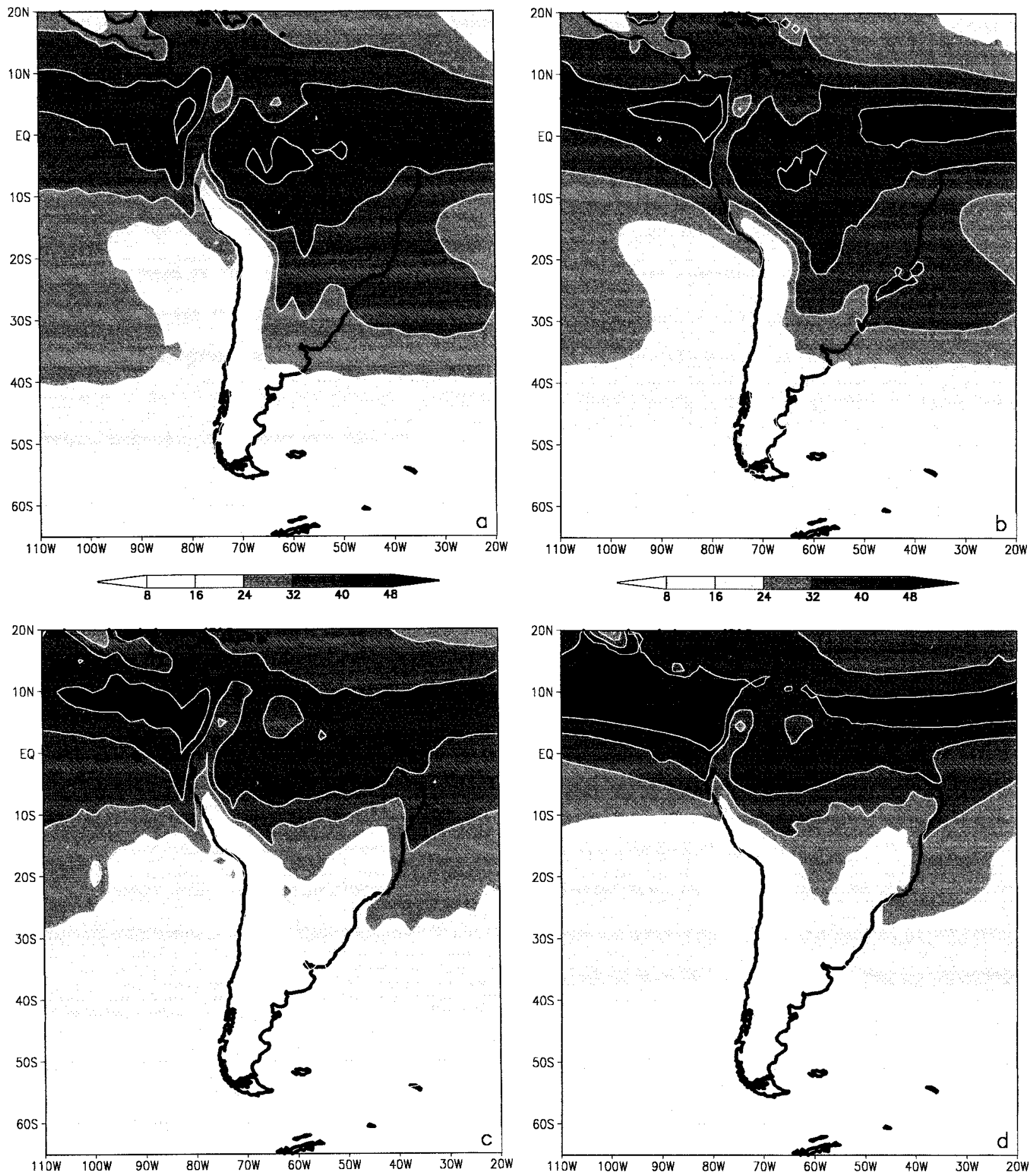

FIG. 3. Southern Hemisphere summer (upper panel) and winter (lower panel) mean total precipitable water obtained from [(a) and (c)] the NNRP database, period: 1976-97, and [(b) and (d)] from the National Aeronautics and Space Administration Water Vapor Project, period: 1988-95, database. Contour interval: $8 \mathrm{~mm}$.

prominent over the Amazon basin during the SH summer, which is in good agreement with other observations. Notice, however, that the location of the rainfall rate maximum over the Amazon basin in the NNRP summer field (about $5^{\circ} \mathrm{S}, 43^{\circ} \mathrm{W}$ ) is coincident with neither its position in the observed climatologies nor with the location of this precipitable water maximum (Figs. $2 a$ and $3 a$ ). 
Another precipitable water maximum clearly seen during the SH summer is the one located over the SACZ, which is in good correspondence with the precipitation maximum (Figs. 2a and 3a), a characteristic already noticed by Rao et al. (1996). However, higher atmospheric water vapor content is not associated with the winter precipitation maximum indicated by the NNRP farther south of the SACZ summer location and with similar orientation, as described in the previous section.

In the $\mathrm{SH}$ winter (Figs. $3 \mathrm{c}$ and $3 \mathrm{~d}$ ), the ridge in the precipitable water field, which extends southward in the subtropical central part of the continent during summer, recedes toward lower latitudes, which is in correspondence with a northward shift of the Amazon basin rainfall maximum.

\section{c. The evaporation rate}

Like precipitation, NNRP evaporation data are a model product forced by the data assimilation procedure. Surface fluxes of heat, moisture, and momentum are parameterized following the Monin-Obukhov similarity theory. The formulation is based on Miyakoda and Sirutis (1986). Once the turbulent exchange coefficients have been computed, bulk aerodynamic formulas are used to obtain the fluxes. The model uses a temperatureindependent latent heat of evaporation coefficient. Then, multiplying the latent heat flux $\left(\mathrm{W} \mathrm{m}^{-2}\right)$ by the appropriate factor (0.034 56), the evaporation rate is obtained in $\mathrm{mm} \mathrm{day}^{-1}$.

An observed climatology of the evaporation rate is not available for comparison within the whole region. However, data from the First International Land Surface Satellite Climatology Project (ILSCP) Field Experiment (FIFE) in Kansas were used by Betts et al. (1996) to assess the diurnal and seasonal cycles of the land surface energy budget in the NCEP-NCAR reanalysis. A good agreement was found in a climatic sense, though a more detailed daytime and nighttime comparison of surface fluxes show some discrepancies.

When the annual mean of the balance equation, (1), averaged over the region of study, is considered, the precipitation and the evaporation rates are almost equal, and they amount to about $3 \mathrm{~mm}$ day $^{-1}$. However, the mean evaporation rate over the continent increases up to $4 \mathrm{~mm} \mathrm{day}^{-1}$ in summer and decreases to $2.8 \mathrm{~mm}$ day $^{-1}$ in winter. Over the adjacent oceans, the annual variation is much smaller in amplitude, with a maximum of $3.3 \mathrm{~mm} \mathrm{day}^{-1}$ in fall and a minimum of $3.0 \mathrm{~mm} \mathrm{day}^{-1}$ in spring. As a result of the relative variation of $P$ and $E$, the continental area behaves as a sink of atmospheric water vapor averaged over the year, with maximum absolute value of $P-E$ in summer and minimum in winter. Instead, the adjacent oceans behave as a permanent source of atmospheric water vapor, with maximum intensity in summer and minimum intensity in winter-spring (see Table 5).

Figures $4 \mathrm{a}$ and $4 \mathrm{~b}$ show the $\mathrm{SH}$ summer and winter
TABLE 5. Seasonal and annual mean evaporation minus precipitation rate $E-P\left(\mathrm{~mm} \mathrm{day}^{-1}\right)$, for the total region indicated in Table 1 and for the continental and oceanic subregions, obtained from the NNRP database.

\begin{tabular}{lrrrrr}
\hline \hline & Summer & \multicolumn{1}{c}{ Fall } & Winter & Spring & Annual \\
\hline$(E-P)_{\text {TOTAL }}$ & 0.2 & 0.1 & 0.1 & -0.1 & 0.1 \\
$(E-P)_{\text {OCEAN }}$ & 0.9 & 0.7 & 0.4 & 0.3 & 0.6 \\
$(E-P)_{\text {LAND }}$ & -1.9 & -1.7 & -0.8 & -1.6 & -1.5 \\
\hline
\end{tabular}

mean evaporation rate obtained from the NNRP. Complementing the regional statistics provided in Table 5, the summer and winter spatial distribution of $P-E$ shown in Figures $4 \mathrm{c}$ and $4 \mathrm{~d}$ indicate the location of the main sinks and sources of atmospheric water vapor.

The highest evaporation rates in the region are found on the equatorial side of the tropical anticyclones, with a maximum in the $\mathrm{SH}$ winter. Along the Perúvian and Ecuadorian coasts north of $20^{\circ} \mathrm{S}$ and in the eastern equatorial Pacific, oceanic upwelling and the resulting lower sea surface temperature is associated with low evaporation rates. Consistently, the generally high precipitation rates in low latitudes have a relative minimum in the equatorial zone when the ITCZ is next to the region. However, this minimum fades away during spring when the ITCZ is located in its northernmost position far from the Equator.

The evaporation rate is high over the warm Brazilian Current and relatively low over the cold current of Malvinas (Falkland). The contrast is clearly seen in the area of confluence of both currents in the southwestern Atlantic between $35^{\circ}$ and $40^{\circ} \mathrm{S}$. Another evaporation rate maximum occurs to the east of the de la Plata river mouth during the $\mathrm{SH}$ fall and winter. This can contribute to the frequent development of baroclinic synoptic disturbances that characterize the region, as indicated by the eddy growth rate estimates of Berbery and Vera (1996). High evaporation rates also occur in the relatively warmer water of the continental shelf from $40^{\circ} \mathrm{S}$ to the southern end of the continent.

No relative maximum in the summer field of evaporation rate can be appreciated in the SACZ (Figs. 2a and $4 \mathrm{a}$ ). This shows that local evaporation is not the main cause of the precipitable water and rainfall maxima and the associated intense convective activity in the region. This will be later confirmed when analyzing the atmospheric water vapor flux field.

During the SH summer, the abundant precipitation, increased evapotranspiration, and intense warming produce high evaporation rates all over the Amazon basin and the southeastern part of the continent (southern Brazil, eastern Paraguay, and northeastern Argentina). However, we cannot discern any evaporation maximum at about $5^{\circ} \mathrm{S}, 43^{\circ} \mathrm{W}$, where the NNRP data locate the highest rainfall rate in the region (Figs. $2 \mathrm{a}$ and $4 \mathrm{a}$ ). This maximum should be linked to the atmospheric water vapor transport, as will be seen in the next section.

A narrow strip of high evaporation rate extends along 

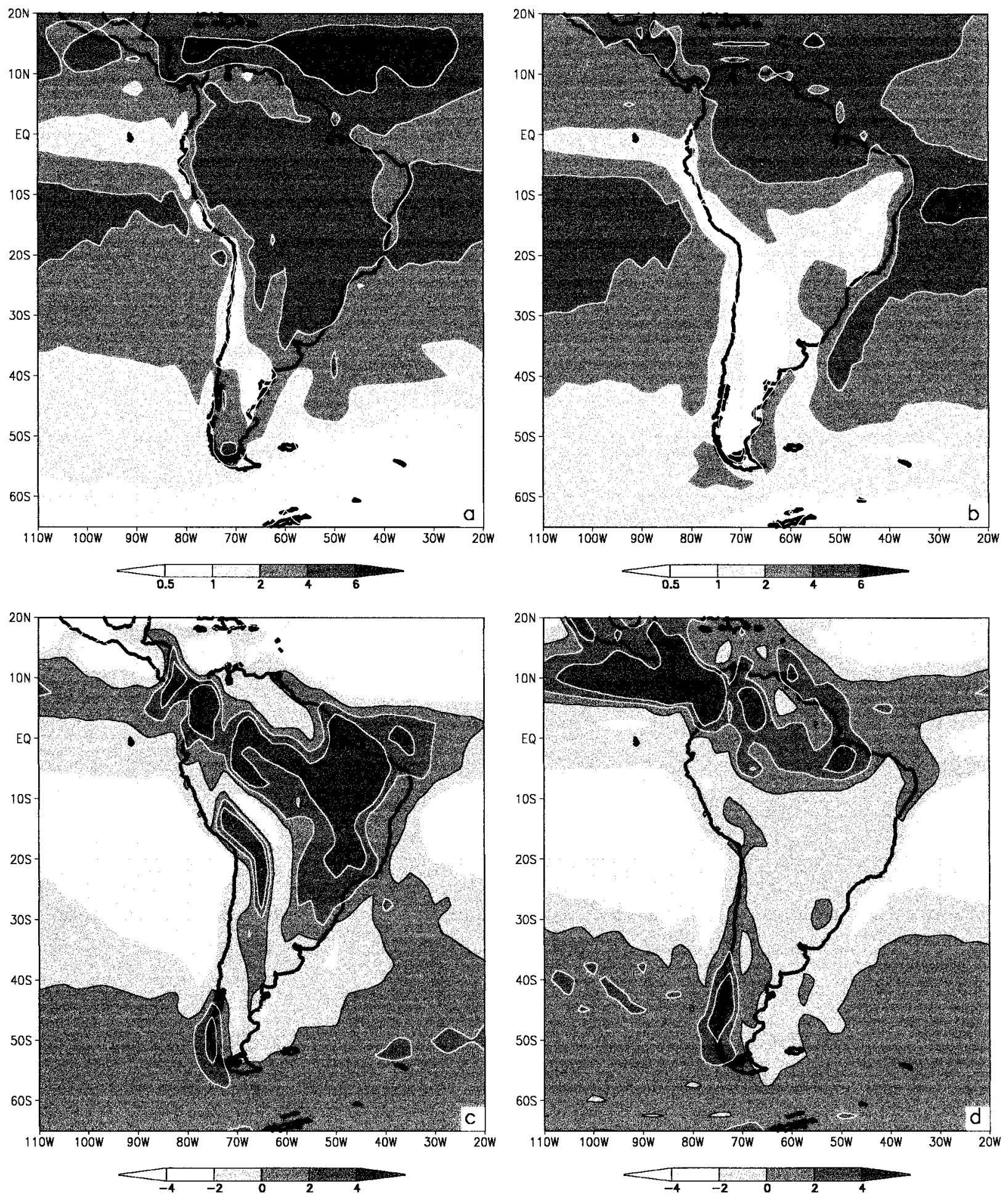

FIG. 4. Upper panel: Southern Hemisphere (a) summer and (b) winter mean evaporation rate obtained from the NNRP database, period: 1976-97. Contours at 0.5 and $1.0 \mathrm{~mm} \mathrm{day}{ }^{-1}$ and higher contours at $2 \mathrm{~mm} \mathrm{day}^{-1}$ intervals. Lower panel: (c) summer and (d) winter mean precipitation minus evaporation rate. Contour interval: $2 \mathrm{~mm} \mathrm{day}^{-1}$. A solid black line indicates the $0 \mathrm{~mm} \mathrm{day}^{-1}$ contour. 
the eastern slope of the central Andes up to about $30^{\circ} \mathrm{S}$ during spring-summer, which agrees with a seasonal rainfall peak in the same region (Fig. 2a). Farther south, the scarce precipitation and the limited soil water availability in the semiarid subtropical part of the continent is consistent with the low evaporation rate throughout the region.

In the southern end of the continent, on the lee side of the Andes, there is a maximum in the evaporation rate in spring-summer. This can be the combined result of a large amount of water available in the soil due to snow melting, the intensity and persistence of the prevailing westerly flow, and the increment in the net incoming solar radiation as the snow coverage decreases.

\section{The water vapor transport and the large-scale circulation over South America}

The relationship between the annual precipitation cycle and relevant characteristics of the atmospheric circulation in South America is discussed in this section on the basis of an analysis of the stationary and transient components of the atmospheric water vapor flux, as defined in (5). Some brief comments about previous findings are appropriate here.

Using cloud winds derived from geostationary satellite images, Virji (1981) describes the summer circulation in the upper- and lower-tropospheric levels over northern and central South America up to $35^{\circ} \mathrm{S}$. This study conforms to previous findings based on a rather sparse network of aerological observations about the existence of an extended anticyclonic circulation in the summer upper troposphere, known as the Bolivian high, and a trough over northeast Brazil. The Bolivian high is maintained by a warm-core system whereas the downstream trough over northeast Brazil is characterized by a cold core (Chu 1985). An intense cross-equatorial flow linking the anticyclonic circulation with the Northern Hemisphere jet stream, generalized ascending motions over the Amazon basin, and descending motions over northeast Brazil are some of the outstanding upper-level circulation features first noticed by Virji (1981). In the lower troposphere, in addition to the northeastern trade winds blowing from the north Atlantic deep into the Amazon basin, the same author highlights the existence of a northwestern jet-like flow along the eastern slope of the central Andes. In summer, a low pressure system intensifies in the Paraguay-Argentinean Chaco $\left(25^{\circ} \mathrm{S}\right.$, $58^{\circ} \mathrm{W}$ ), and this jet flow merges with the Atlantic anticyclonic circulation on the southeastern side of the continent.

The vertically integrated horizontal flux of water vapor over South America is investigated by Rao et al. (1996) using a 5-yr period of the ECMWF analysis. This study emphasizes the importance of the northeastern trade winds and the tropical anticyclonic circulation over the South Atlantic Ocean in conveying water vapor toward the Amazon basin during summer and, even far- ther, across the southeast coast of Brazil back to the Atlantic. The convergence of this tropospheric flow becomes important over central Brazil in October, reaches its maximum in January, and begins to fade away in April, as it is evidently associated with the evolution of the rainfall season in the region. Likewise, Rao et al. (1996) point out the correspondence between water vapor flux convergence and precipitation in northeastern Brazil during April and in the extreme northwest of South America during July. These authors consider the contribution of the water vapor transport by the transient flux less important than that of the stationary flux in low latitudes and midlatitudes. Our results show that the convergence of both flux components reaches comparable magnitude in some regions south of $30^{\circ} \mathrm{S}$, having also an opposite influence on the rainfall distribution.

Zhou and Lau (1998) relate the outstanding climatic features of the rainfall and the tropospheric circulation over tropical and subtropical South America, providing arguments about the existence of a large-scale monsoon circulation. They emphasize the importance of the sensible and latent heating over the Bolivian plateau and southeastern Brazil during summer with regard to the generation and maintenance of a continent-ocean thermal contrast, which is able to develop such an extended circulation. This is in agreement with the recent results of Lenters and Cook (1997), confirming the role of the latent heating over the Amazon basin, central Andes, and SACZ in the generation and maintenance of the Bolivian high and the northeast Brazil Low.

The results described in the next sections validate many of the features of the vapor transport indicated in earlier studies. However, little information about the factors affecting the atmospheric water vapor balance south of $35^{\circ} \mathrm{S}$ is provided in the previous works. Our analysis encompasses the entire South American continent for a time period longer than that of any preceding study and focuses on the interaction between the stationary and transient components of the water vapor flux in the humid-to-dry transition zone in the southern part of the continent.

\section{a. The stationary water vapor flux $\mathbf{Q}_{s}$}

Figure 5 shows the stationary water vapor flux $\mathbf{Q}_{s}$ and, by means of contour levels, its horizontal convergence field $\left(-\boldsymbol{\nabla} \cdot \mathbf{Q}_{s}\right)$ during the SH summer and winter. From this figure, an intense westward water vapor flux stands out throughout the year between $10^{\circ} \mathrm{N}$ and $5^{\circ} \mathrm{S}$, in correspondence with the equatorial band of trade winds and the relatively high levels of precipitable water in these latitudes. An even narrower band of water vapor flux convergence is seen inside the area of westward vapor flux over the equatorial oceans and adjacent continental zones. This feature is consistent with the intense convective activity and high rainfall rates typical of the ITCZ. The convergence is fed by the vapor flux coming 

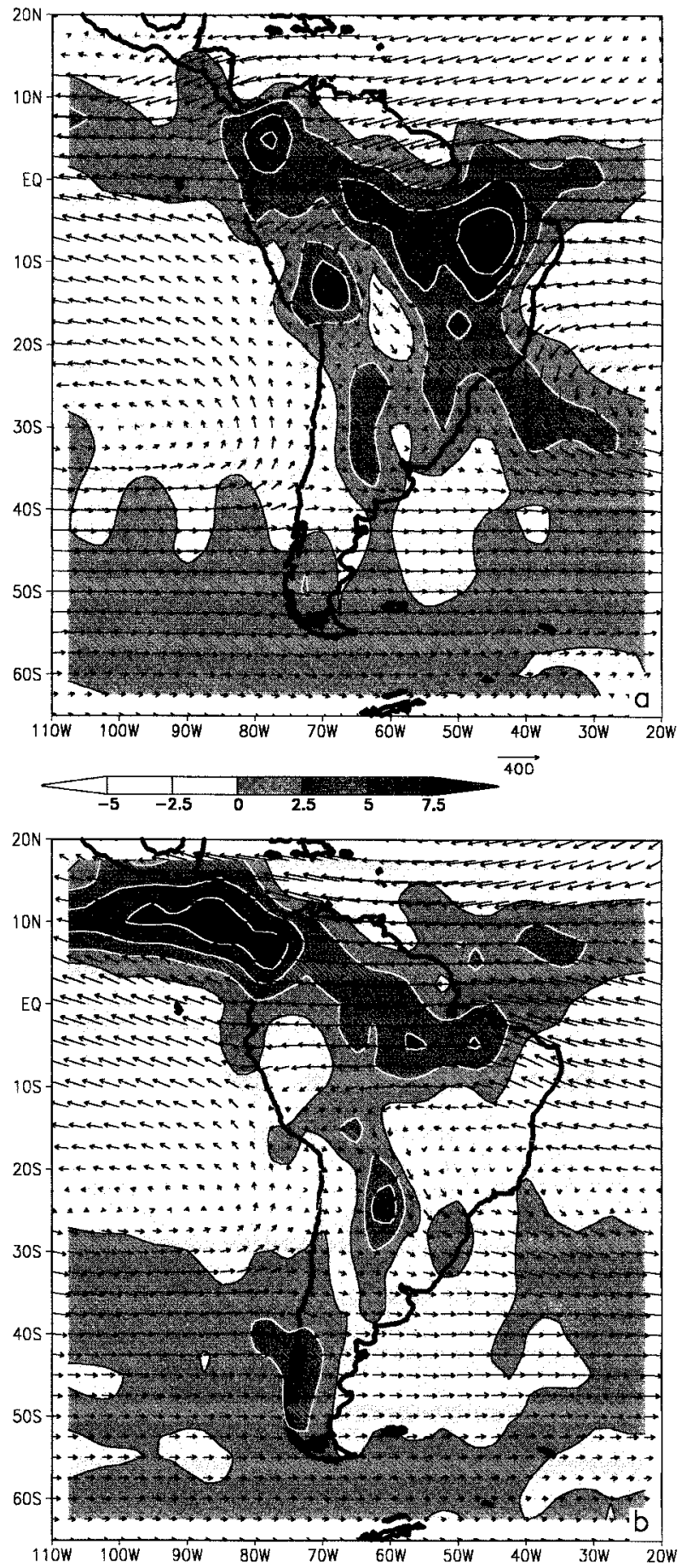

FIG. 5. Horizontal stationary water vapor flux field $\mathbf{Q}_{\text {: }}$ : (a) summer and (b) winter. The magnitude is expressed in $\mathrm{mm} \mathrm{m} \mathrm{s}{ }^{-1}$, and the vector scale is indicated in the bottom right. The convergence of the vector field $\left(-\boldsymbol{\nabla} \cdot \mathbf{Q}_{s}\right)$ is indicated by contour lines, with a contour interval of $2.5 \mathrm{~mm} \mathrm{day}^{-1}$. A solid black line indicates the $0 \mathrm{~mm} \mathrm{day}^{-1}$ contour. from the equatorial side of the subtropical anticyclones, oceanic areas characterized by high evaporation rate and water vapor flux divergence, especially during each hemisphere's winter. Two maxima are distinguished within the near-equatorial convergence zone. One is located on the western side of the continent and extends toward the Pacific Ocean during the $\mathrm{SH}$ winter (Fig. 5b) and spring, when the ITCZ is in its northernmost position. The other is symmetrically located on the eastern side of the continent and extends toward the Atlantic Ocean during summer (Fig. 5a) and fall, when the ITCZ is in its southernmost position.

The presence of high elevations in the northern Andes at about $5^{\circ} \mathrm{N}$ possibly contributes to channeling the easterly water vapor flux along the northern and southern slopes of the obstacle. This, in turn, could develop zonal convergence on the windward side and meridional convergence on the lee side. This is a more noticeable feature during the SH winter-spring, when the ITCZ is far north of the equator, and the region consistently experiences its highest rainfall rates.

The high rainfall rate over the Amazon basin is the combined result of convergence in the stationary water vapor flux and intense evaporation. In particular, the summer precipitation maximum on the eastern side of the Amazon basin (about $5^{\circ} \mathrm{S}, 43^{\circ} \mathrm{W}$ ) is the consequence of a maximum in the flux convergence (Fig. 5a). However, this center should be located $15^{\circ}$ to the west inorder to agree with the observed location of the rainfall maximum (Fig. 2b).

According to Lenters and Cook (1995), the water vapor convergence over the Amazon basin is mainly zonal and is associated with a counterclockwise rotation of the northeasterly trade winds as they flow into the continent, becoming northwesterly winds when they reach the Andes foothills. The Hastenrath (1997) study suggests that the summer $200 \mathrm{hPa}$ level circulation (not shown in the figures) links the nucleus of high convective activity and precipitation rate over the Amazon basin with the nucleus of subsidence in the southern flank of the north Atlantic anticyclone. The latter could, in turn, affect the strength of the northeasterly trade winds that feed water vapor into the high convective region, suggesting a positive feedback.

During the SH summer, the area of water vapor flux convergence over the Amazon basin extends southward along the eastern part of the continent, accompanying the geographical expansion of the rainy season toward southern Brazil, northeastern Argentina, eastern Paraguay, and Uruguay. It also extends southeastward toward the Atlantic Ocean between $20^{\circ}$ and $30^{\circ} \mathrm{S}$, consistent with the development of the SACZ. This extended convergence zone is the result of the confluence of the northwesterly winds flowing parallel to the Andes foothills toward the fully developed continental low, the northeasterly winds coming from the South Atlantic high, and the midlatitude westerly flow on the southern boundary. The area of convergence over the eastern 


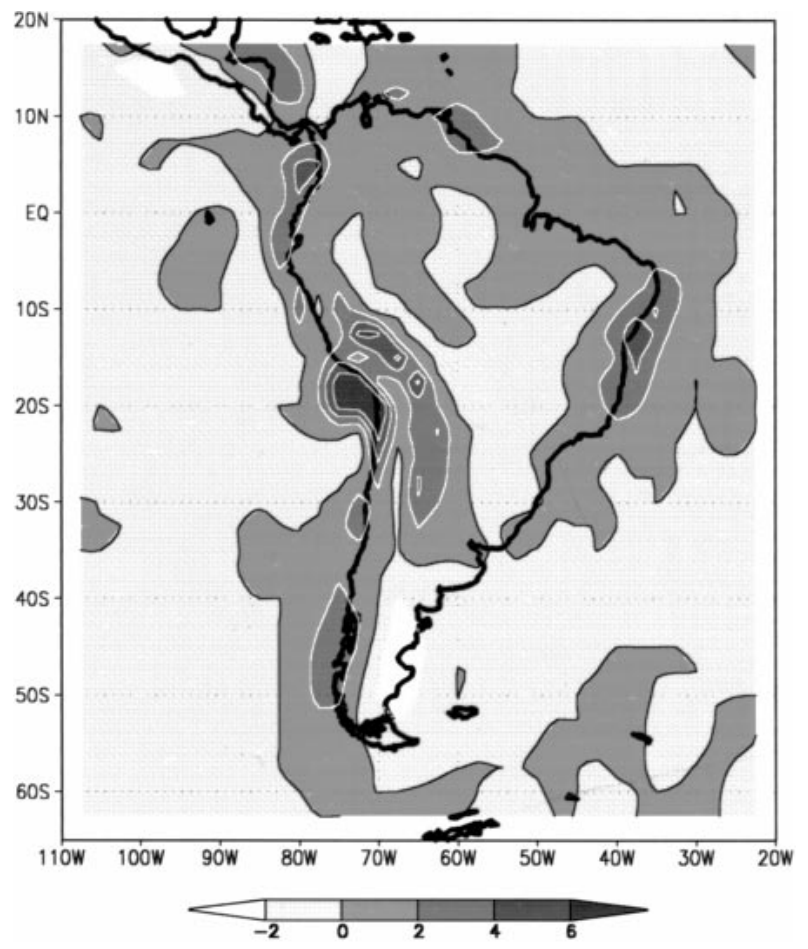

FIG. 6. Annual mean field of the vertical water vapor flux convergence- $(q \omega)_{s} / g \rho_{w}$ [see (4)]. Contour interval: $2.0 \mathrm{~mm} \mathrm{day}^{-1}$. A solid black line indicates the $0 \mathrm{~mm} \mathrm{day}^{-1}$ contour.

portion of the continent begins to withdraw during fall, signaling the onset of the dry season. It reaches a minimum extension in winter (Fig. 5b), when the continental low almost disappears and the equatorial water vapor flux becomes approximately zonal.

A conspicuous convergence maximum is observed on the northeastern and eastern slope of the central Andes between $10^{\circ}$ and $20^{\circ} \mathrm{S}$ throughout the year. It intensifies during the SH summer months in correspondence with a short rainy season characteristic of this part of the continent. In the NNRP fields, this convergence maximum is located at a lower level over this slope of the Andes than the rainfall maximum, and it is possibly overestimated (see comments on computation errors in $\mathbf{Q}$ in section 3). Consequently, a significant negative imbalance occurs in the region, as shown in Fig. 1a. The vertical convergence of the water vapor flux could be another important contribution to the rainfall rate along the same slope of the central Andes due to forced topographic uplift of the north-northwesterly flow, as Fig. 6 indicates. Qualitatively, these results agree with those derived from numerical experiments by Lenters and Cook (1995). However, this contribution also seems to be overestimated, increasing the negative imbalance (cf. Figs. 1a and 1b).

On the western slope of the central Andes the vertical convergence is equal to or greater than that on the eastern slope. According to results of the aforementioned numerical experiments, this should be compensated by horizontal divergence in correspondence with typical low rainfall rates throughout the region (Schwerdtfeger 1976). This is not the case in the NNRP results, which also show a large imbalance on the western slopes of the central Andes (Fig. 1b).

Between the two meridional bands of water vapor flux convergence and high rainfall rate, one on the eastern slope of the central Andes and the other along southeastern Brazil, there is a narrow band of stationary water vapor flux divergence during summer (Fig. 5a). This band overlies a region of relatively low precipitation rate in the NNRP field not noticeable in any of the sets of observed data considered (Fig. 2a). Thus, this particular feature of the stationary water vapor flux cannot be confirmed.

South of $20^{\circ} \mathrm{S}$ and along the central part of the continent, there is a narrow band of convergence in the stationary water vapor flux present throughout the year. It seems to be an extension of the maximum over the eastern slope of the central Andes, but it has some distinctive features. During the $\mathrm{SH}$ winter, it reaches $30^{\circ} \mathrm{S}$, while in summer, it extends up to $40^{\circ} \mathrm{S}$ but is always limited to the south by the latitude of the westerly flow. As it will be seen in the next section, the divergence of the transient water vapor flux almost balances this center of stationary convergence, producing a steep meridional rainfall gradient over the subtropical part of the continent.

South of $40^{\circ} \mathrm{S}$, westerly winds prevail throughout the year. A north-south elongated area of water vapor flux convergence is found where the westerly vapor flux hits the southern Andes. This area of convergence increases in longitudinal extension and intensity during fall and winter as the westerly flow extends farther north. During this time of year, the northward shift of the Pacific anticyclone and the development of a ridge in the surface pressure field over the continent south of $40^{\circ} \mathrm{S}$ (Schwerdtfeger 1976) produce a zonal component in the pressure gradient over the western side of the continent. As a result, a southward component in the wind flow appears as it enters the continent. The corresponding water vapor flux vector rotation (Fig. 5b) and the uplift forced by the Andes (Fig. 6) increase the stationary water vapor flux convergence, consistent with an increase in the rainfall rate during the cold season. The semiarid plateau of Patagonia to the east of the southern Andes is in contrast with the rainy western slope. It has an annual rainfall average of less than $200 \mathrm{~mm}$, which reflects the effects of the horizontal (Fig. 5) and vertical (Fig. 6) divergence of the stationary water vapor flux during most of the year. This stationary divergence is partly balanced by transient flux convergence, as will be shown below.

\section{b. The water vapor flux due to transient perturbations $\mathbf{Q}^{\prime}$}

Figure 7 shows the transient water vapor flux $\mathbf{Q}^{\prime}$ and its horizontal convergence $\left(-\boldsymbol{\nabla} \cdot \mathbf{Q}^{\prime}\right)$ for the $\mathrm{SH}$ summer 

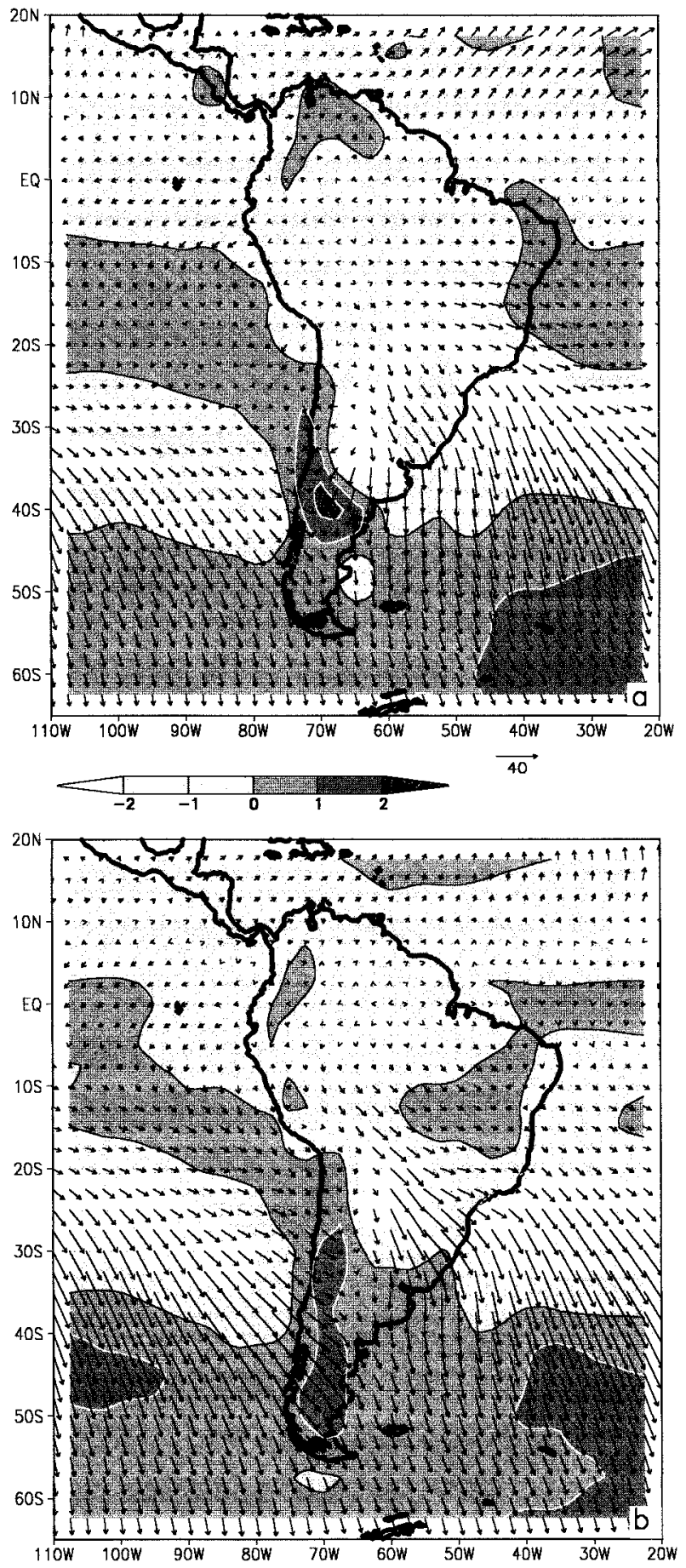

FIG. 7. Horizontal transient water vapor flux field $\mathbf{Q}^{\prime}$ : (a) summer and (b) winter. The magnitude is expressed in $\mathrm{mm} \mathrm{m} \mathrm{s}^{-1}$, and the vector scale is indicated in the bottom right. Note the change in the vector scale with regard to Fig. 5. The convergence of the vector field $\left(-\boldsymbol{\nabla} \cdot \mathbf{Q}^{\prime}\right)$ is indicated by contour lines. Contour interval: 1.0 $\mathrm{mm}$ day $^{-1}$. A solid black line indicates the $0 \mathrm{~mm}$ day $^{-1}$ contour. and winter. South of the equator, the water vapor fluxdue to wind and specific humidity transient perturbations-has a dominant southward component and a smaller eastward component throughout the year. The transient flux is, in general, an order of magnitude lower than the stationary flux and in the opposite direction of the gradient of tropospheric water vapor content. The southward component of the transient flux in the ocean regions reaches a maximum intensity between $30^{\circ}$ and $50^{\circ} \mathrm{S}$, feeding water vapor into the region of the storm tracks (Trenberth 1991), and its magnitude becomes comparable to the same component of the stationary flux.

An outstanding climatic feature of the water vapor transport due to perturbations is a dipole structure in the field of the water vapor flux convergence over the continent (Fig. 7), which could be related to the rainfall spatial distribution. It is located between about $20^{\circ}$ and $40^{\circ} \mathrm{S}$ and shows a latitudinal displacement as well as changes of intensity throughout the year. One pole of the couplet is an area of transient water vapor flux convergence located over the region of scarce precipitation, running across the continent from northern and central Chile up to extreme southeastern Argentina. This pole is also coincident with an area of divergence in the stationary flux. The other pole of the couplet is an area of transient water vapor flux divergence located over the rainy region to the northeast and east of the previous one and approximately coincident with an area of convergence in the stationary flux. The magnitude of the convergence/divergence couplet in the transient flux is even greater than the mean precipitation rate in the zone. However, the transient flux brings water vapor into the dry continental belt while the stationary flux drains water vapor out of this region. Within the relatively humid zone to the northeast of the semiarid lands, the transient and stationary flux components have an opposite behavior. The net effect of the transient flux convergence is the narrowing and tempering of the continental subtropical dry zone. The semiarid zone is bounded to the north by the region of the subtropical summer rainfall regime. The location of this boundary seems to depend critically on the time and space variation of the approximately in-balance stationary and transient water vapor fluxes over the region.

The subtropical ocean zones, where the stationary circulation is dominated by the South Pacific and South Atlantic anticyclones, are characterized by a strong transient flux divergence on their polar side. Combining this with the stationary water vapor flux results in a southward extension of the total flux divergence zone. An exception, however, occurs during the SH spring and summer, when an area of stationary flux convergence develops next to the continent in the southwestern Atlantic between $20^{\circ}$ and $30^{\circ} \mathrm{S}$ (Fig. 5a), exceeding in magnitude the transient flux divergence. This yields a net water vapor flux convergence (the total water vapor flux field is not shown in the figures) consistent with 
the rainfall maximum that characterizes the SACZ. In this oceanic region, there is an association between the stationary and transient flux components, characterized by their comparable magnitude and opposite sign, similar to that over the continent.

\section{Discussion and conclusions}

The characteristics of the main components of the atmospheric water vapor balance over South America and adjacent oceans were analyzed using the 22-yr period, spanning from 1976 to 1997, of the NCEP-NCAR reanalysis project database. A special emphasis was given to clarify the role of the large-scale atmospheric circulation in the spatial and seasonal variation of the rainfall rate.

The NNRP mean seasonal fields of precipitation and atmospheric water vapor content were compared with the GPCP and NVAP observed datasets, respectively. A good statistical level of similarity between the reanalysis and observations is found in both variables over the region of study. However, some disagreement in the precipitation rate over the eastern slope of the central Andes and in the location of the maximum rainfall over the Amazon basin has been noticed.

The vertically integrated water vapor flux was decomposed into its stationary and transient components, and the corresponding divergence fields were computed. The physical consistency of the seasonal and spatial variation of all these fields was examined. The annual mean balance adequately closes over the ocean regions and most of the continental area; however, large imbalances are observed over mountainous regions. These imbalances are likely due to errors in the finite difference computation of the vertically integrated water vapor flux and its divergence in the vicinity of high topography. The interpolation procedure applied to pressure levels above the surface can also be affected by nonnegligible errors over steep topography, which will propagate in the water vapor flux and flux divergence computations. Far from the Andes, the analysis performed lets us judge the relative importance of the local evaporation rate and of the stationary and transient water vapor flux components in the resulting spatial distribution of the mean seasonal precipitation rate.

The stationary water vapor flux convergence plays an important role in producing the following rainfall rate maxima: over the ITCZ and on both slopes of the northern Andes throughout the year, in the Amazon basin, along the eastern slope of the central Andes, in the southeastern part of the continent and the SACZ during summer, and on the western slope of the southern Andes during winter.

The direction of the vertically integrated transient water vapor flux is in general downgradient of the total precipitable water, and its magnitude reaches a maximum in midlatitudes, where wind velocity perturbations are larger. As Watterson (1998) suggests, this compo-

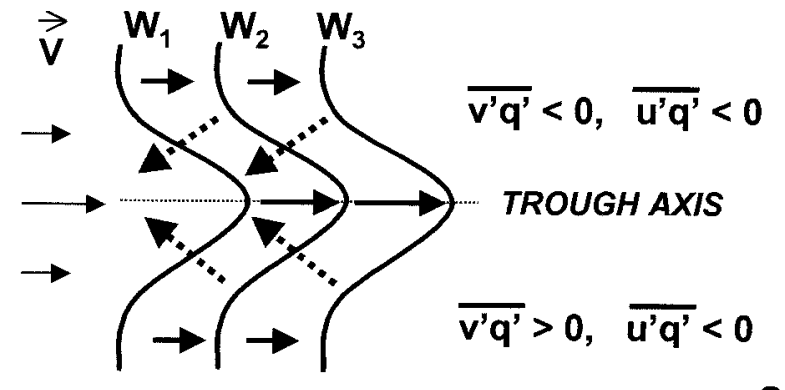

a)

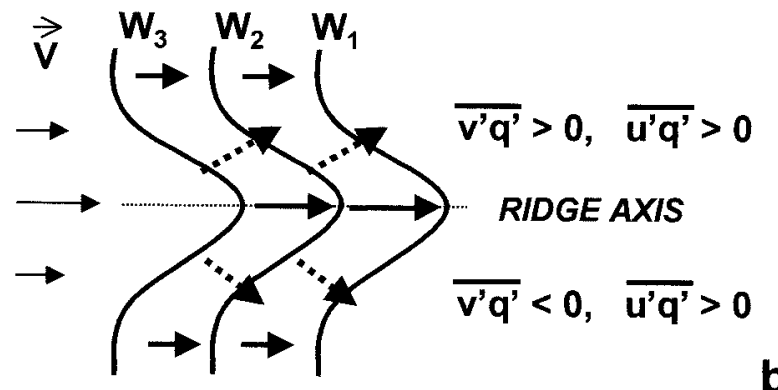

b)

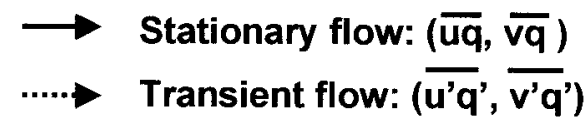

FIG. 8. Schematic representation of the interaction between the stationary and transient components of the water vapor flux. (a) Water vapor trough produced by a stationary flow in the same direction of the water vapor content gradient $(\nabla W)$ and the associated convergent water vapor flux due to transient perturbations. (b) Water vapor ridge produced by a stationary flow in the opposite direction to the water vapor content gradient and the associated divergent water vapor flux due to transient perturbations.

nent of the water vapor transport is potentially consistent with a Fickian theory for small-scale turbulent eddy transfer. In the one-dimensional case, it could be expressed as

$$
\partial \mathbf{Q}_{x} / \partial t=-K_{x} \partial W / \partial x,
$$

where $K_{x}$ is a positive eddy-diffusion coefficient, which can be made proportional to the magnitude of the eddy velocity components through an appropriate mixinglength scale.

Although the magnitude of the transient water vapor flux convergence is, in general, lower than that of the stationary flux, in some oceanic and continental regions they are comparable, and a dynamic link may exist between them. A simple transport-gradient model of the transient flux, like (7), may also help to clarify this particular functioning. Two representative cases of the mechanisms involved are sketched in Fig. 8. In one of them (Fig. 8a), a jetlike stationary flow in the direction of the specific humidity gradient produces a dry tongue (trough) in the humidity field. Note, we have adopted in Fig. 8 the mathematical definition of gradient, $\nabla W$, instead of the meteorological usage, $-\nabla W$. Perturbations of the velocity field coming from the region of 
lower specific humidity will produce negative humidity perturbations away from it. Negative (positive) wind velocity perturbations perpendicular to the stationary flow tend to be positively (negatively) correlated with specific humidity perturbations to the south (north) of the water vapor trough axis, while wind velocity perturbations parallel to the stationary flow tend to be negatively correlated with specific humidity perturbations everywhere. This results in a convergent water vapor transient flux toward the dry tongue. A similar reasoning explains the divergence of the transient water vapor flux away from the humidity ridge produced by a stationary flow in the opposite direction to the specific humidity gradient (Fig. 8b). In both cases, the net effect of the transient flux is to erode the relative extremes in the humidity field created by the stationary flow. A further question arises here: how would the atmospheric circulation and stationary and transient flux respond to a relative maximum in the atmospheric water vapor content created by a relative maximum in the $P-E$ rate?

As already noticed by Lenters and Cook (1995), an example of the case depicted in Fig. 8b can be found in SACZ during summer (cf. Figs. 3a, 5a, and 7a). In this region, the convergence in the stationary flux creates a ridgelike pattern in the water vapor content, while the divergence in the transient flux tends to smooth it out.

An example of combined ridge-trough patterns is seen over the continent, associated with a dipole structure in the convergence of the transient water vapor flux. Figure 9 shows the summer mean wind vector and specific humidity fields at the $925-\mathrm{hPa}$ pressure level. Also indicated in this figure is the boundary between the poles of the couplet in the transient water vapor flux convergence field shown in Fig. 7a. A noticeable northeasterly flow over the central and eastern part of the continent and a southwesterly flow over the western side contribute to create the observed ridge-trough structure in the specific humidity field, north of $40^{\circ} \mathrm{S}$. As Fig. 7a indicates, a divergent transient water vapor flux develops over the low-level humidity ridge and a convergent flux develops over the trough. Both patterns, similar to those depicted in Fig. 8b and 8a, respectively, tend to temper the strong water vapor gradient throughout the region. It is important to notice that this kind of interaction between the stationary and transient components of the water vapor flux can determine the seasonal location of the boundary between the humid and dry zones in the southern part of the continent. This interaction could help to explain the relation between anomalies in the atmospheric circulation and interannual or longer rainfall rate fluctuations over very productive agricultural regions in the southern part of the continent.

Acknowledgments. Most of the figures were created using the PC-GrADS software. We want to thank Dr. Arlindo da Silva, from Data Assimilation Office, NASA Goddard Space Flight Center for his assistance using

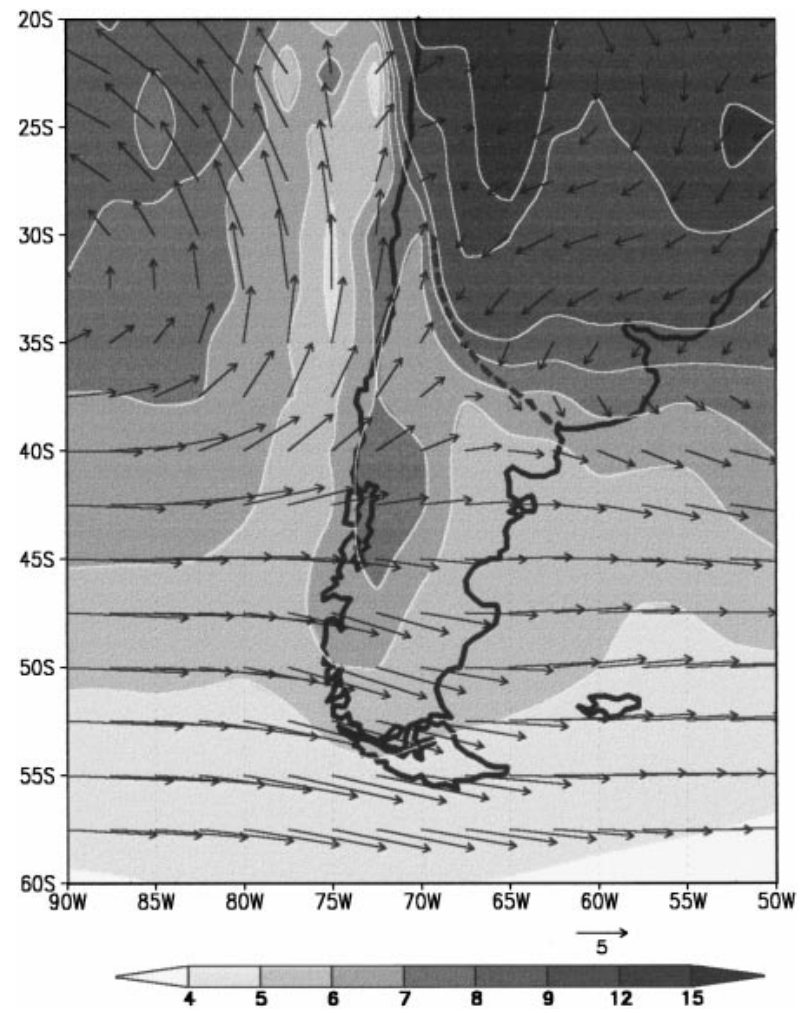

FIG. 9. SH summer mean wind vector $\left(\mathrm{m} \mathrm{s}^{-1}\right)$ and specific humidity $\left(\mathrm{g} \mathrm{kg}^{-1}\right)$ fields, at the 925-hPa pressure level, obtained from the NNRP database. A dashed line indicates the boundary between the convergent and divergent zones in the transient water vapor flux, shown in Fig. 7a.

GrADS. The authors are especially grateful to Andrés Rivas and Patricia Dell'Arciprete for carefully reviewing the manuscript and for their valuable comments throughout our research. The National Research Council of Argentina (CONICET) supported the work through Grant PIA-6386/97 and the Secretary of Science and Technology (SECyT), ANPCyT, Argentina, through Grant PICT97: 07-00000-00561.

\section{REFERENCES}

Berbery, E. H., and C. S. Vera, 1996: Characteristics of the Southern Hemisphere winter storm track with filtered and unfiltered data. J. Atmos. Sci., 53, 468-481.

Betts, A. K., S.-Y. Hong, and H.-L. Pan, 1996: Comparison of NCEPNCAR reanalysis with 1987 FIFE data. Mon. Wea. Rev., 124, $1480-1498$.

Chu, P. S., 1985: A contribution to the upper-air climatology of tropical South America. J. Climatol., 5, 403-416.

Hastenrath, S., 1997: Annual cycle of upper air circulation and convective activity over the tropical Americas. J. Geophys. Res., 102, 4267-4274.

Huffman, G. J., and Coauthors, 1997: The Global Precipitation Climatology Project (GPCP) combined precipitation dataset. Bull. Amer. Meteor. Soc., 78, 5-33.

Jaeger, L., 1976: Monatskarten des Niederschlags für die ganze Erde (Monthly maps of precipitation for the whole world). Tech. Rep. 18, No. 139, 33 pp. and plates. [Available from Bibliothek des 
Deutschen Wetterdienstes, Frankfurter Str. 135, 63067 Offenbach, Germany.]

Kalnay, E., and Coauthors, 1996: The NCEP/NCAR 40-Year Reanalysis Project. Bull. Amer. Meteor. Soc., 77, 437-471.

Kodama, Y. M., 1992: Large-scale common features of subtropical precipitation zones (the Baiu frontal zone, the SPCZ, and the SACZ). Part I: Characteristics of subtropical frontal zones. $J$. Meteor. Soc. Japan, 70, 813-836.

Legates, D. R., and C. J. Willmott, 1990: Mean seasonal and spatial variability in gauge-corrected, global precipitation. Int. J. Climatol., 10, 111-127.

Lenters, J. D., and K. H. Cook, 1995: Simulation and diagnosis of the regional summertime precipitation climatology of South America. J. Climate, 8, 2988-3005.

_ and _ 1997: On the origin of the Bolivian high and related circulation features of the South American climate. J. Atmos. Sci., 54, 656-677.

Miyakoda, K., and J. Sirutis, 1986: Manual of the E-physics, 87 pp. [Available from Geophysical Fluid Dynamics Laboratory, Princeton University, P.O. Box 308, Princeton, NJ 08542.]

Moura, A. D., and J. Shukla, 1981: On the dynamics of droughts in northeast Brazil: Observations, theory, and numerical experiments with a general circulation model. J. Atmos. Sci., 38, 26532675.

Peixoto, J. P., and A. H. Oort, 1992: Physics of Climate. American Institute of Physics, $520 \mathrm{pp}$.
Randel, D. L., T. H. Vonder Haar, M. A. Ringerud, G. L. Stephens, T. J. Greenwald, and C. L. Combs, 1996: A new global water vapor dataset. Bull. Amer. Meteor. Soc., 77, 1233-1246.

Rao V. B., I. F. A. Cavalcanti, and K. Hada, 1996: Annual variation of rainfall over Brazil and water vapor characteristics over South America. J. Geophys. Res., 101, 26 539-26 551.

Rasmusson, E. M., and K. C. Mo, 1996: Large-scale atmospheric moisture cycling as evaluated from NMC global analysis and forecast products. J. Climate, 9, 3276-3297.

Schwerdtfeger, W., 1976: Climates of Central and South America. Vol. 12, World Survey of Climatology, Elsevier, $532 \mathrm{pp}$.

Trenberth, K. E., 1991: Storm tracks in the Southern Hemisphere. $J$. Atmos. Sci., 48, 2159-2178.

Virji, H., 1981: A preliminary study of summertime tropospheric circulation patterns over South America estimated from cloud winds. Mon. Wea. Rev., 109, 599-610.

Watterson, I. G., 1996: Nondimensional measures of climate model performance. Int. J. Climatol., 16, 379-391.

, 1998: An analysis of the global water cycle of present and doubled $\mathrm{CO}_{2}$ climates simulated by the CSIRO general circulation model. J. Geophys. Res., 103, 23 113-23 129.

Yanai, M., and T. Tomita, 1998: Seasonal and interannual variability of atmospheric heat sources and moisture sinks as determined from NCEP-NCAR reanalysis. J. Climate, 11, 463-482.

Zhou, J., and K.-M. Lau, 1998: Does a monsoon climate exist over South America? J. Climate, 11, 1020-1040. 